\title{
O Laser e suas Complicações
}

\author{
Merlo I. ${ }^{1}$ \\ ${ }^{1}$ Rio de Janeiro - Brasil. \\ e-mail: ivanesio.merlo@terra.com.br
}

Merlo, I. 2013. O Laser e suas Complicações, p.62. In: Bastos, Francisco Reis. Anais do V Simpósio Internacional de Flebologia [Blucher Medical Proceedings n.1 v.1]. São Paulo: Blucher, 2014 http://dx.doi.org/10.5151/medpro-flebo-SIF_37
Costuma-se dizer que, o médico em sua rotina de trabalho, dificilmente poderá prescrever um medicamento, instituir um tratamento, seja clinico ou cirúrgico, sem que haja possibilidade de complicações ou efeitos colaterais. Assim, o tratamento das varizes com laser transdérmico, para as telangiectasias e "microvarizes", ou endolaser no tratamento cirúrgico, também se incluem nesse aforismo.

Como todo tratamento médico, há sempre um período de aprendizado inicial onde essas complicações e intercorrências são mais frequentes. Entretanto, essa tendência tem sido observada com maior frequência especialmente quando, o laser no tratamento de varizes, é utilizado por outras especialidades médicas e paramédicas, do que por angiologistas e cirurgiões vasculares.

Em conclusão, a forma mais efetiva de reduzir esse problema esta no conhecimento fisiopatologia da doença em questão, afinidade com os equipamentos e técnica utilizada, aliados ao bom senso e prudência.

Palavras-chave: laser, complicações do laser, IVC, tratamento de varizes, varizes. 